\title{
The effect of the argumentation method on student success
}

\author{
Hüseyin Polat ${ }^{1 \mathrm{a}}$, Fatma Bilge Emre ${ }^{1,2}$, and Nilay Aydoğan ${ }^{3}$ \\ ${ }^{I}$ Department of Elementary Education, Faculty of Education, İn̈nü University, Malatya, 44280, Turkey \\ ${ }^{2}$ Prof. Dr. Hikmet Sayllkan Advanced Materials Research an Application Laboratory, Scientific and Technological \\ Research Center, Inönü University, Malatya, 44280, Turkey \\ ${ }^{3}$ Department of Science and Mathematics Education, Faculty of Education, Inönü University, Malatya, 44280, \\ Turkey
}

\begin{abstract}
The objective of this study is to research into the effect of the argumentation method of study on the success of 7 th grade primary school students in regard to the atomic structure. This study was conducted in a primary school located in the District of Doğanyol, the City of Malatya during 2nd term of 2013-2014 school years. The sampling of this study consists of 25 students in total, 12 of whom are male and 13 of whom are female. This is a quasi-experimental study in which a pre-test and a posttest were performed. In the data analysis, the T-test was performed for the unrelated samples. According to the data obtained as the result of the test/experiment, a significant difference was found in favor of the experimental group.
\end{abstract}

Keywords. Structure of atom; argumentation method; the effect of the argumentation method; science education.

\section{Introduction}

In our century called the Space Age, the world has been going through a major and rapid transformation that also leads to changes in social requirements along with it. The changes taking place in the present century, particularly those in the field of technology, also alter the society's expectations from an individual. The society needs to research more into the fields of science and mathematics while, at the same time, requiring well-supported and equipped individuals who are aware of the needs of the present age, with the ability to criticize and question issues $[8,16]$. Different social structures, such as industry, economy and communication are in need of raising individuals capable of utilizing technology [10].

A good scientific education and training is required for the purpose of manifesting the desire to change within the society, since scientific education comprises producing the information/knowledge about the natural world, or creating and utilizing the necessary tools in order to understand the world [29] as well as enabling students to gain positive behaviors regarding technology [12].

\footnotetext{
a Corresponding author: h.polat44@hotmail.com
} 
Hançer et al. [12] define one of the main objectives of scientific education as raising individuals who will be able to catch up with the scientific age that changes and advances rapidly every moment. In order to ensure this, the argumentation method could be used in education. The argumentation method, besides allowing for different and logical ways of thinking, also promotes attaining the cognitive and metacognitive processes. Moreover, this method both develops the individual's reasoning strategy and empowers his/her understanding $[21,2]$.

\section{Toulmin Argumentation Method and Its Place in Physical Sciences}

Although argumentation is a concept as ancient as the history of humanity, it was Toulmin who made contribution to education through scientific argumentation. Toulmin resembled the process of argumentation to a living organism and stated that the concept of argumentation was the coordination of theories and evidences put forward to support or disprove a descriptive result, model or supposition, also adding that it was necessary to turn the argumentation into a given format in order not to miss out the important points within that argumentation [25, 27].

Also translated into Turkish as the scientific discussion, argumentation can be expressed as the process in which individuals make claims to solve a particular problem and try to prove the accuracy of their ideas in the presence of the other party by setting forth reasons that support such claims [20]. Argumentations may dismiss a theory as well as promoting it [7]. Toulmin argumentation model consists of claims, data, reasons, support and the elements of disproof and characterization. A claim, datum and reason can be considered among the basic components of an argument. Along with the basic components in a more complicated argumentation can supportive, restrictive and negatory elements also be seen, which contribute to the validity and quality of an argument $[1,19]$.

The argumentation method has become one of the most frequently referred methods in scientific education in recent years. When the literature was reviewed, it was observed that throughout the process in which the argumentation method had been applied, the fact that the instructor/teacher had prepared an environment where the students could express themselves, advocate their ideas and study in cooperation with each other easily had encouraged the students in problem-solving, mounting an argument and supporting claims $[13,1]$.

One of the main objectives of scientific literacy is to enable the students to become aware of the processes that scientists apply in acquiring scientific knowledge. Ensuring the students' active participation in decision-making processes has also increased the importance of the argumentation method in scientific education [19]. Teachers can utilize argumentation to encourage their students and to develop their talents of reasoning in the dialogues concerning science. Mounting an argument and a counter-argument is an effective method to strengthen the students' capacity of reasoning and understanding [21].

In the classrooms where the argumentation method was applied, the students who normally never had the chance to speak out were observed to have had the opportunity to express themselves, thanks to which they became more active in the class [28]. The method of learning science through performance and writing, which is one of the applications of this method, was seen to have made the science lessons more enjoyable [11].

Argumentation is seen to be quite an effective method on the student success $[29,14$, $17,22,4,20]$. In this study, we researched into the effect of the argumentation method on the student success regarding the atomic structure. The problem of this study is as follows: "The Effect of the Argumentation Method on the success of 7th grade students as regards atomic structure". 


\section{Method}

In this study, the effect of the argumentation method on the success of 7 th grade students as regards atomic structure was investigated. The study was conducted in a primary school located in the District of Doğanyol, the City of Malatya during the 2nd term of 2013-2014 school years. The sampling of this study consisted of 25 students in total, 12 of whom were male and 13 of whom were female. The period of this study lasted for 10 class- hours, during which a success test consisting of 30 questions used as the pre-test and the post-test was applied. The questions within the success test were obtained from the exams concerning the 7th grade level, which was performed in the previous years by The Ministry of National Education. Thus, no study was performed as to the internal consistency of the test in question. An expert opinion was asked for the content validity, and an approval regarding the compliance of the test in terms of content validity was received, as well.

According to the pre-test result, two homogeneous groups were formed in terms success and gender. The activities in the books delivered by The Ministry of National Education as the course books were applied to the control group. For the experimental group, on the other hand, worksheets regarding the atomic structure were prepared by starting, as a reference, from the worksheets which were accepted in terms of their significance and validity and which were formerly prepared and applied by Yeşiloğlu [29] in relation to the subject of gases. The $t$ test was performed over the findings obtained from the study for the unrelated samplings.

\section{Findings}

In this study, the pre-test and post-test were applied. According to the results obtained from the pre-test, the sampling was divided into two groups in order to ensure homogeneity. The $t$ test was performed over the data obtained from the pre-test, and the results were shown in Table 1.

Table 1.t-test results according to the pre-test (preliminary) data

\begin{tabular}{|c|c|c|c|c|c|c|}
\hline Groups & $\mathrm{N}$ & $\bar{X}$ & sd & $\mathrm{df}$ & $\mathrm{t}$ & $\mathrm{p}$ \\
\hline Experimental Group & 13 & 31,80 & 12,06 & 23 &,- 094 & ,926 \\
\hline Control Group & 12 & 32,22 & 10,37 & & & \\
\hline
\end{tabular}

According to the result of the unrelated samples ttest performed on the groups formed as the result of the pre-test data results, it was seen that there was no significant difference between the pre-test mean score ( $=31.80)$ of the students in the group determined as the experimental group and the pre-test mean score $(=32.22)$ of the students in the group determined as the control group [ $\mathrm{t}(23)=-0,094, \mathrm{p}>0.05]$. According to these results, the experimental and control groups can be said to be homogeneous in terms of their success scores.

At the end of 10 class- hours, the post-test was applied to the control and experimental groups. The ttest was performed in line with the data obtained from the post-test, and the results were given in Table 2 . 
Table 2.t-test results according to the post-test data

\begin{tabular}{lllllll}
\hline Groups & $\mathrm{N}$ & $\bar{X}$ & $\mathrm{sd}$ & $\mathrm{df}$ & $\mathrm{t}$ & $\mathrm{p}$ \\
\hline Experimental Group & 13 & 64,77 & 18,18 & 23 & 2,094 &, 048 \\
Control Group & 12 & 50,00 & 16,99 & & & \\
\hline \multicolumn{1}{c}{$(p<.05)$} & & & & & &
\end{tabular}

According to the result of the unrelated samples ttest performed to test whether or not the argumentation method had a significant effect on the student success regarding the atomic structure, a significant difference $[\mathrm{t}(23)=2,094, \mathrm{p}<0.05]$ was seen between the posttest mean scores of the students in the experimental group to which the argumentation method was applied $(=64.77)$ and the post-test mean scores of the students in the control group to which the argumentation method was not applied $(=50.00)$. In this case, the argumentation method can be stated to be a positively effective method on the student success regarding the atomic structure.

\section{Discussion}

Considering the results achieved through the analysis of the data obtained from this study in which the effect of the argumentation method on student success is analyzed, a significant difference $[\mathrm{t}(23)=2,094, \mathrm{p}<0.05]$ was seen between the students of the experimental group $(=64.77)$ and those of the control group $(=50.00)$ in terms of the post-test. In relation to the atomic structure, the argumentation method can be said to be more effective on the student success when compared with the conventional methods or the learning techniques contained within the teachers' guide books, which also suggests an outcome in compliance with the studies in the literature.

In a study conducted on the Earth and the Universe by Ceylan [4], it was observed that there was a significant difference in favor of the experimental group as to the academic success.

In the study conducted by Kabataş Memiş [14] on the units regarding The Electricity in our Lives, and Matter and Heat, it was seen that there was a significant difference in favor of the experimental group in the last test application performed in this matter. In the first permanence test performed for the matter involved, there was a significant difference in favor of the experimental group in both of the units, whereas in the second permanence test, no significant difference was observed in the unit called Matter and Heat.

Kingir [17], in his study concerned with the 9th grade subject referred to as The Chemical Changes and Mixtures, saw that the group which studied through the argumentation method had better understood the concepts in regard to the chemical changes and mixtures when compared with the conventional method.

In a study conducted by Özkara [22] on Pressure, it was seen that there was a significant difference in favor of the experimental group in terms of success.

In the study conducted by Günel et al. [11], where the effect of the Approach of Learning Science through Performance and Writing on the attitude of self-evaluation towards science and scientific success was analyzed, it was emphasized that the Approach of Learning Science through Performance and Writing had led to a significant difference on the student success in favour of the experimental group and that there was a positive improvement in the attitudes of the students in the experimental group towards the lesson. 
In the study conducted by Ceylan [3], where the effect of the Argumentation-Based Science Learning Approach (ABSLA) on the students' academic success was analyzed during their class referred to as The Laboratory of Plant Physiology, it was concluded that there was a significant difference in terms of success in favour of the experimental group to which ABSLA was applied.

The argumentation method, apart from the student success, is also an effective method in teaching concepts and in conceptual changes [29, 24]. Argumentation is a more effective method than the conventional one in understanding the concepts concerning the subject/topic and in being able to solve the questions related to the concepts and principles over the subject at issue. Similarly, this method still produces effective results when also used along with different methods of learning $[13,6,15,26,5]$.Considering the studies in the involved literature, the argumentation method is also seen to be an effective way of teaching socio-cultural subjects $[9,18$ and 23].

\section{Result and Suggestions}

In this study, where the effect of the argumentation method of study on the student success in regard to the atomic structure was analyzed, the expected result could be achieved in consequence of the unrelated samples ttest performed in accordance with the pre-test result. It was seen according to the pre-test results that there was no significant difference [ $t(23)=$ $-0,094, p>0.05]$ between the students of the experimental group $(=31.80)$ and those of the control group $(=32.22)$. On the other hand, according to the unrelated samples ttest results performed in terms of the post-test, there was a significant difference $[t(23)=2,094, p<0.05]$ observed between the students of the experimental group $(=64.77)$ and those of the control group $(=50.00)$.

According to the ttest result as the result of the post-test result performed at the end of the study, on the other hand, it is seen that there is a significant difference $(p=0.024)$ between the control group $(=50.00$; $\mathrm{sd}=16,996)$ and the experimental group $(=64.615$; $\mathrm{sd}=18,029)$. This outcome suggests that the method of argumentation has an impact on the student success. However, this obtained result is limited with both the atomic structure and the sampling of the study. Eventually, considering the sampling, the significant difference that occurred between the experimental and the control groups in terms of success resulted from the method of argumentation, and this outcome suggests the fact that the argumentation method poses a significant difference in a positive way on the student success. When the literature is reviewed, it is seen that there are other conducted studies that support this outcome $[3,11,14,17,22,4]$.

The argumentation method is seen to be an effective method in teaching concepts or in subjects like conceptual changes $[29,24]$. In order to reach the desired result in the course of applying the argumentation method, the quality of the question to be asked by the teacher is of great importance. The questions asked should be cognitively top-level ones according to Bloom taxonomy for the continuity of the process, in other words, for the permanency of this method [11]. Including argumentation in scientific education is possible with qualified teachers/instructors. It is required that studies with in-service teachers and the teacher candidates with a bachelor's degree be conducted in line with his objective through the argumentation method, which is also one of the targets of Scientific Education.

In the classrooms where the argumentation method is applied, a comfortable atmosphere should be provided in the first place so that the students can express themselves freely and easily. This is the major factor in reaching the desired result. Despite the convenient setting provided, several conditions such as the crowded classrooms, the students' insufficient state of readiness and the necessity to complete the schedule before the deadline make it difficult to perform in-class applications of argumentation. Separately, 
there is also the need for experienced teachers with the skill to perform the argumentation method.

Considering the in-class applications of the argumentation method, it was seen that the 6th grade primary school students could use data and reasons against a claim put forward, whereas they failed to use extensive arguments comprising more than one disproving factors [1].

The students' level of readiness must also be taken into consideration in the argumentation method. The students must be at such a level that they will be able to notice the differences cognitively in order to mount and perform an argumentation. According to Okumuş [20], the students have a basic trouble as to what is being explained through claims, data and reasoning when they fail to be at a certain level in the cognitive sense.

It has been stated that argumentation is an important educational method in increasing cognitive thinking skills and the levels of success [7]. Furthermore, it was seen that when the argumentation method was used along with different methods of teaching, positive results could be achieved, as well [6,15 and 5], and in addition, this method could be used as an efficient way of teaching socio-scientific subjects and increasing sensitivity in this matter [9, 18 and 23].

\section{References}

1. Aymen Peker, E., Apaydın, Z., \& Taş, E. Understanding of Heat Insulation with Argumentation: Case Study with Primary 6th Grade Students. Dicle University Journal of the Institute of Social Sciences, 4(8), 79-100, (2012).

2. Böttcher, F., \& Meisert, A. Argumentation in Science Education: A Model-based Framework. Science Education, (20), 103-140, (2011).

3. Ceylan, Ç. Implementing the Science Writing Heuristic (SWH) Approach in Science Laboratory Activities (Master Thesis). Gazi University Institute of Education Sciences, Ankara, (2010).

4. Ceylan, K. E. Teaching 5th Grades Elementary Students with Scientific Argument Based Method in the Area of World and Universe Learning (Master Thesis).Gazi University Institute of Education Sciences, Ankara, (2012).

5. Cin, M. Effects of concept cartoon activities based-argumentation method on students' conceptual understanding levels and scientific process skills (Master Thesis). Dokuz Eylül University Institute of Education Sciences, İzmir, (2013).

6. Demirbağ, M. The Effect of Multi Modal Instruction on Student's Science Achievement and Writing Skills in an Argument Based Inquiry Classroom (Master Thesis). Ahi Evran University Institute of Science Education, Kırşehir, (2011).

7. Deveci, A. Developing Seventh Grade Middle School Students' Socio scientific Argumentation, Level of Knowledge and Cognitive Thinking Skills in the Structure of Matter Subject (Master Thesis).Marmara University Institute of Education Sciences, İstanbul, (2009).

8. Doğru, M., Gençosman, T., Atakalın, A. N., \& Şeker, F. Analysis of the Postgraduate and Doctoral Theses Conducted On Sciences Education. Journal of Turkish Science Education, 9(1), 49-66, (2012).

9. Domaç, G. G. The Effect Of The Argumentation - Based Learnings In Terms Socio scientific Issues In Biology Education (Master Thesis). Gazi University Institute of Education Sciences, Ankara, (2011).

10. Gül, Ş., \& Yeşilyurt, S. The Effect of Computer Assisted Instruction Based Constructivist Learning Approach on Students' Attitudes and Achievements. Necatibey Faculty of Education Electronic Journal of Science and Mathematics Education, 5(1), 94-115, (2011). 
11. Günel, M., Memiş Kabataş, E., \&Büyükkasap, E. Effects of the Science Writing Heuristic Approach on Primary School Students' Science Achivement and Attitude towards Science Course. Education and Science, 35(155), 49-62, (2010).

12. Hançer, A. H., Şensoy, Ö.\&Yıldırım, H. İ. An Evaluation about the Importance of Contemporary Science Education at Elementary Schools and How This Kind of Science Teaching Must Be. Pamukkale University Institute of Education Sciences, 1(13), 80-88, (2003).

13. Jime'Nez-Aleixandre, M. P., Rodriguez, A. B., \&Duschl, R. A. "Doing the Lesson" or "Doing Science": Argument in High School Genetics. Science Education, (84), 757792, (2000).

14. Kabataş Memiş, E. Effects Of The Argumentation Based Science Learning Approach And Self Evaluation On Primary School Students' Science And Technology Course Achievement And Retention Of The Achievement (Doctoral Dissertation) Atatürk University Institute of Educational Sciences, Erzurum, (2011).

15. Karışan, D. An Exploration of Pre service Science Teachers' Written Argumentation Skills Regarding the Global Climate Change Issue (Master Thesis). Yüzüncü Y1l University Institute of Science, Van, (2011).

16. Kenar, İ., \&Balçı, M. The Development of Attitudes toward Science and Technology Lesson Scale: The Case of 4th and 5th Grade Primary School Students. Dumlupinar University Journal of Social Sciences, (34), 201-210, (2012).

17. Kıngır, S. Using the Science Writing Heuristic Approach to Promote Student Understanding In Chemical Changes and Mixtures (PhD Thesis). METU, Ankara, (2011).

18. Kırbağ Zengin, F., Keçeci, G., Kırılmazkaya, G., \&Şener, A. Elementary School Students learning about Nuclear Power Plants with the On-Line Scientific Argumentation Learning Program. Presentation: the 5th International Computer and Instructional Technologies Symposium, Elazı̆̆, (2011).

19. Kutluca, A. Y. Investigating Of Pre-Service Science Teachers' Socio-Scientific and Scientific Argumentation Quality In Terms Of Content Knowledge Level (Master Thesis).Abant İzzet Baysal University Institute of Educational Sciences, Bolu, (2012).

20. Okumuş, S. The Effects of Argumentation Model on Students' Achievement and Understanding Level on the Unit of "States of Matter and Heat" (Master Thesis). Karadeniz Teknik University Institute of Educational Sciences, Trabzon, (2012).

21. Osborne, J. F. An Argument for Arguments in Science Classes. R\&D, (2010).

22. Özkara, D. Teaching Pressure Subject To Eighth Class Students With Activities Based On Scientific Argumentation (Master Thesis). Adiyaman University Institute of Science, Adiyaman, (2011).

23. Soysal, Y. Influence of Content Knowledge Level to Socio scientific Argumentation Quality: Genetically Modified Organisms (Master Thesis). Abant İzzet Baysal University Institute of Educational Sciences, Bolu, (2012).

24. Tekeli, A. The Effect of an Argumentation-Centered Class Environment on the Conceptual Change about Acid-Base and the Understanding Nature of Science (Master Thesis).Gazi University Institute of Educational Sciences, Ankara, (2009).

25. Toulmin, S. E. The Uses of Argument (Updated Edition). New York: Oxford University Press, (2003).

26. Tümay, H., \& Köseoğlu, F. Developing Pre-Service Chemistry Teachers' Understandings of Teaching through. Journal of Turkish Science Education, 8(3), 105119, (2011).

27. Yalçın Çelik, A. An Analysis Of The Influences Of The Teaching Approach Based On Scientific Argumentation On High School Students' Conceptual Understanding, 
Attitudes, And Willingness For Argumentation And The Quality Of Argumentation (PhD Thesis) Gazi University Institute of Educational Sciences, Ankara, (2010).

28. Yeşildağ- Hasançebi, F., \& Günel, M. Effects of Argumentation Based Inquiry Approach on Disadvantaged Students' Science Achivement. Elementary Education Online, 12(4), 1056-1073, (2013).

29. Yeşiloğlu, S. N. Teaching Gases Topic to High School Students through Argumentation (Master Thesis).Gazi University Institute of Educational Sciences, Ankara, (2007). 